\title{
International Tourism, Digital Infrastructure, and CO2 Emissions: Fresh Evidence From Panel Quantile Regression Approach
}

Liu Wei

Qinghai Normal University

Sana ullah ( $\square$ sana_ullah133@yahoo.com )

Quaid-i-Azam University https://orcid.org/0000-0003-3431-9776

\section{Research Article}

Keywords: International tourism, Digital infrastructure, CO2 emissions

Posted Date: October 20th, 2021

DOI: https://doi.org/10.21203/rs.3.rs-912790/v1

License: (c) (i) This work is licensed under a Creative Commons Attribution 4.0 International License. Read Full License 


\section{Abstract}

The main motivation behind this study is the importance of the tourism sector and digitalization in the economic development of a country and their potential effects on the country's environmental quality. For empirical analysis, the study applies FMOLS, DOLS, and quantile regression techniques for Asian economies. The findings of the study confirmed that tourism and digitalization improve environmental quality in FMOLS and DOLS models. In the basic quantile regression model, the estimates attached to tourism arrival are positive $5^{\text {th }}$ quantile to $40^{\text {th }}$ quantile and then turn negative from $60^{\text {th }}$ quantile and onwards. Likewise, the estimates attached to tourism receipts in the robust quantile regression model are positive from quantile $5^{\text {th }}$ to quantile 20 and negative and increasing from quantile 30 and onwards. Conversely, the estimates of digital infrastructure are insignificant in the basic quantile model at all quantiles except $95^{\text {th }}$. However, the estimated coefficients of digital infrastructure in the robust model are negative and rising from $40^{\text {th }}$ quantile to $70^{\text {th }}$ quantile and negative and declining from $80^{\text {th }}$ quantile to $95^{\text {th }}$ quantile. In general, we can say that as the tourism and digital sectors grow, the $\mathrm{CO} 2$ emissions decline.

\section{Introduction}

An incredible intensification of economic events has been detected in the previous few decades and, combined with this bang in universal economic actions, there has been a swift increase in worldwide greenhouse gasses emissions (Aslam et al. 2021; Hussain et al. 2020). It is observed that the colossal upsurge in $\mathrm{CO}_{2}$ discharges, weather variation, and the unexpected temperature increase is because of intricate phenomena arising from a complicated collaboration amid energy, growth, and the environment. Though energy is called a chief contributor to economic growth; however, it is considered as the main source of carbon releases (Belaïd and Zrelli 2019). Carbon production is linked with the increased use of energy due to rising economic activities (Khattak et al. 2020). The need to cut CO2 emissions at a sustainable level is essential than ever; thus, it is considered the hottest topic among the international community. Consequently, it is indispensable to recognize the determinants of carbon emissions that would enable the whole world to reach a consensus regarding policies to mitigate the effects of global heating.

The share of carbon emissions in greenhouse gasses is more than $80 \%$, hence, it is the most common indicator used for environmental quality. All the actions that contribute to foster economic activities also add $\mathrm{CO}_{2}$ to the atmosphere. The substantial increase in tourism enlarges the world economy, produces jobs, and stimulates exports. Apart from wealth and job creation, its swift development has added to the worries of the international community about sustainability. The use of non-renewable and unclean energy in this sector has exerted negative impacts on environmental quality (Gokmenoglu and Eren 2020). According to Tugcu and Topcu (2018), tourism not only generates income but also increases the present stock of $\mathrm{CO}_{2}$. In 2016, the share of tourism in terms of carbon emissions was almost $5 \%$ of the world's total emissions and this is expected to increase $5.3 \%$ by the year 2030 (UNWTO 2019). Due to the rising share of tourism in carbon emissions, it has become imperative for economists, environmentalists, and policy-makers to test the nexus between the environment and tourism. A plethora of studies have examined the tourism-led growth hypothesis and, to some extent, there is unanimity among them that tourism stimulates economic growth (Aslan et al. 2020). However, this growth is not free rather it comes at the expense of economic, social, and environmental decay (Azam et al. 2018). Positive shocks in tourism and transportation surely lead to increase energy demand that will eventually stir the environmental crisis like weather variation and heating of the globe (Katircioglu et al. 2014). The UNWTO (2019) observed that, in the year 2018, the total number of tourists jumped to 1.4 billion and this number is expected to reach 1.7 billion by the year 2030. Tourism-tempted economic activities have attracted almost US\$ 1.7 trillion. Hence, it is quite obvious for nations to try to catch a fair share of this inside this economic cycle and the increasing tourism industry. However, the important question is how to separate the goods of tourism from its bad i.e. how to promote tourism by not damaging the environment? From this viewpoint, we can say that tourism is significant in understanding the relationship between economic growth and the environment and achieving sustainable development.

Theoretically, the excellence of the environment with constant economic growth is called a medium to examine the "sustainability of a country" (Khattak et al. 2020). The continuous growth in tourism, over the last few decades, and its contribution to both the pillars of sustainable development i.e. economic growth and environmental quality has induced the researchers to include the variable of tourism in the production as well as environment functions. As far as tourism-environment nexus is concerned two strands of studies with opposing views are available. The first study in this context is by Bach and Gößling (1996) who attempted to disclose the relationship between tourism and environmental quality and contended that tourism has significantly lead to environmental decay due to an enormous increase in $\mathrm{CO}_{2}$ discharges. This finding was also supported by Goudie and Viles (2013). Moreover, Chan et al. (2018) and Latif et al. (2018) pointed out that tourism contributes to the wastage of water and natural resources that may augment the process of soil erosion and increase the extent of air, water, and land pollution. Furthermore, as the number of tourists in the destination country increase, it will augment the energy consumption, due to a massive increase in transportation, hoteling, and other related services, that will eventually contribute to environmental pollution (Nepal et al. 2019). Conversely, some opine that tourism improves the environmental quality by providing crucial services, encouraging innovations in technology, and promoting the more efficient use of energy. Therefore, we can say that tourism can become a tool to protect the environment if used sensibly (Gössling and Hall 2006; Imran et al. 2014; Naradda Gamage et al. 2017; Dogan and Aslan 2017; Paramati et al. 2018; Akadiri et al. 2018).

Loading [MathJax]/jax/output/CommonHTML/fonts/TeX/fontdata.js 
The role of ICT in increasing economic growth is well established; however, its role in spreading environmental pollution is underexplored. (Chen et al. 2019 and Chien et al. 2021). Given the importance of ICTs in every sector, their usage is growing at the pace of $7 \%$ per annum in the last few decades (Salahuddin et al. 2016). As a result, the energy consumed by the ICTs worldwide had soared to $4.7 \%$ in 2012 against $3.9 \%$ in the year 2007 (Van Heddeghem et al. 2014). Consequently, the share of ICTs in total CO2 emissions has crossed $2 \%$ in 2012 (Greenpeace International, 2014). This confirms the positive role of ICTs in degrading the environmental quality by emitting more CO2 emissions in recent years. ICT can contaminate the environment via two channels: first, during the manufacturing of ICT goods, the factories emit CO2 emissions (Park et al. 2018); second, the increased use of ICTs push the energy demand upward (Moyer and Hughes 2012), which is a primary determinant of environmental degradation (Salahuddin et al. 2016). Conversely, ICT help reduces the reliance on the use of physical materials, or in other words, ICT leads to the dematerialization of the economy, which also lowers the burden on the environment (Usman et al. 2021a; 2021b). Moreover, the energy consumption also decreases because society depends more on e-commercing, virtual meetings, and distance learning instead of physical shopping, business meetings, and classroom learning; hence, lowering the CO2 emissions (Zhang and Liu 2015; Bastida et al. 2019; Ozcan and Apergis 2017).

Sustainable tourism and digital infrastructure are a question that requires serious attention. Tourism is desirable to attain economic development but attached to the enormous consumption of energy, due to transportation and other services, thus promoting $\mathrm{CO}_{2}$ emissions. Hence, it is very pertinent to keep the balance between tourism growth, digital infrastructure, and its hazardous impact on the environment. Against this backdrop, in this study, we have tried to divulge the tourism, digital infrastructure, environment nexus for Asain economies, a first its kind. For Asian economies, tourism and digital infrastructure are a blessing because of their contribution to economic development but the flip side of the story is that they can further speed up the process of environmental degradation in these economies. Hence, discovering the impacts of tourism and digital infrastructure on $\mathrm{CO}_{2}$ emissions in the context of Asian economies is a very pertinent topic.

The composition of the rest of the study is as follows. In section two, the data and estimation methods are elaborated in section two. In section three, we shed light on the results and, finally, concluded the study in section four.

\section{Model And Methods}

Following the previous studies (Zhang and Liu, 2018; Koçak et al. 2020; and Usman et al. 2021), we have developed a model to investigate the relationship between international tourism, digital infrastructure, carbon emissions in Asian economies.

$$
\mathrm{CO}_{2, \mathrm{it}}=\phi_{0}+\phi_{1} \text { Tourism }_{\mathrm{it}}+\phi_{2} \mathrm{DI}_{\mathrm{it}}+\phi_{3} \mathrm{GDP}_{\mathrm{it}}+\phi_{4} \mathrm{EC}_{\mathrm{it}}+\epsilon_{\mathrm{it}}(1)
$$

Where the carbon emission $\left(\mathrm{CO}_{2}\right)$ is a function of international tourism (Tourism), digital infrastructure (DI), GDP per capita (GDP), energy consumption (EC), and random-error term $\left(\epsilon_{\mathrm{it}}\right)$. This study analyzes the long-run relationship between the concerned variables through robust empirical strategies such as fully modified ordinary least squares (FMOLS) and dynamic ordinary least squares (DOLS). The problem of endogeneity is a very common issue while analyzing the Panel data arrangements, and FMOLS and DOLS are reliable techniques to deal with the problem of endogeneity among regressors. Moreover, these techniques are also helpful in resolving the problem of serial correlation between the error terms. Although both approaches help solve the same issues. Still, FMOLS relies on the non-parametric technique to solve the problems of endogeneity and correlation. At the same time, DOLS uses the parametric approach by adding leads and lags to the independent variables to address the problems mentioned above (Kao \& Chiang 2000; Kumar \& Smyth 2007). Another advantage of using DOLS is that it can provide efficient and better results in the case of a small sample size (Danish et al. 2019 and Dogan \& Seker 2016a). The cross-sectional dependence is a serious problem while estimating panel data and, if not taken into account, can give biased results; however, the DOLS method can deal with the problem of cross-sectional dependence by relying on attaining country explicit measurements and giving unbiased, efficient and consistent estimates. Both FMOLS and DOLS can deal with heterogeneity in the long run variance as well as panel cointegration with the help of their weighted criteria.

Various econometric techniques are prevalent to analyze the panel data arrangement. In this study, our technique is quantile regressions, which is a unique choice because it can measure the impact of independent variables on the dependent variable by taking into account the conditional distribution at the various points of the dependent variable. Quantile regression provides robust results even if some of the normality assumptions of the error term are not strictly followed (Koenker and Bassett 1978). This can also be used to project the specifications with censoring (Powell 1984, 1986; Buchinsky, 1994, 1995). Recently, this method has been used to get information with regards to the various points in the dispersal of the regressand by using a method other than the conditional mean (Buchinsky 1994, 1995; Eide and Showalter 1997). The data related to energy and the environment often contains discrete top or heavy tails. As already discussed, this method is superior to OLS because, as opposed to OLS in this technique, we don't have to rely on strict assumptions for the disturbance terms (Koenker and Bassett, 1978). And if a violation occurs, OLS provides biased results, whereas the quantile regression provides efficient and robust estimates. The estimates attached to independent variables in different quantiles are different, meaning that the impact of independent variables on the dependent variables is different across different quantiles. The main problem in estimating the panel data is to deal with unobserved heterogeneity, and the quantile regression method can help resolve the issue by using a penalty term in the procedure of minimization that eradicates the undetected fixed effects (Koenker 2004).

Loading [MathJax]/jax/output/CommonHTML/fonts/TeX/fontdata.js 


\section{Data}

As the focus of the study is to examine the impact of international tourism and digital infrastructure on $\mathrm{CO} 2$ emissions through panel quantile regression approach for time period 1990-2019 for Asian economies. CO2 emissions is a dependent variable that is measured as carbon dioxide emissions in kilotons. International tourism and digital infrastructure are independent variables. Where international tourism is measured through two proxies namely international tourism in number of arrivals (TA) and international tourism in current US\$ receipts (TR). Digital infrastructure is measured by individuals using internet as percentage of population. The study also incorporated some control variables such as GDP measured as GDP per capita at constant 2010 US\$ and energy use that is measured by kg of oil equivalent per capita. All the data for empirical investigation is extracted from the World Bank.

\section{Results And Discussion}

Before executing regression analysis, some preliminary tests are commenced to confirm the time-series properties of data. For investigating the unit root properties of data, we employ the LLC, IPS, and ADF panel unit root tests. Table 1 reports that all the variables are non-stationary at levels but become stationary at their first difference. However, none of the variables is stationary at the second difference. This reveals that all the variables used for estimation purposes are integrated of order one i.e., I(1). Afterward, the study confirmed whether the cross-sectional dependence exists within the panel or not. The existence of cross-sectional dependence among panels can mislead the values of coefficient estimates of the true parameters. Therefore, in order to produce robust coefficient estimates, it is imperative to take into account this issue. In this regard, the study employed Pesaran (2004) test for investigating the cross-sectional dependence. The results in Table 2 show the existence of cross-sectional dependence in the variables.

Table 1

panel unit root tests

\begin{tabular}{|c|c|c|c|c|c|c|c|c|c|}
\hline & LLC & & & IPS & & & ADF & & \\
\hline & $I(0)$ & I(1) & Decision & $I(0)$ & $\mathrm{I}(1)$ & Decision & $I(0)$ & $\mathrm{I}(1)$ & Decision \\
\hline $\mathrm{co} 2$ & -0.235 & -7.980 & $\mathrm{I}(1)$ & -1.235 & $-11.78^{\star \star \star}$ & $\mathrm{I}(1)$ & 0.506 & -6.987 & $\mathrm{I}(1)$ \\
\hline TA & $-2.149 \star * *$ & & $\mathrm{I}(0)$ & -0.907 & $-13.51^{\star \star \star}$ & $\mathrm{I}(1)$ & -0.879 & $-21.26 * \star \star$ & $\mathrm{I}(1)$ \\
\hline $\mathrm{TR}$ & $-6.731^{\star \star \star}$ & & $\mathrm{I}(0)$ & 1.359 & $-3.117^{\star \star \star *}$ & $\mathrm{I}(1)$ & -1.235 & 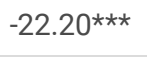 & $\mathrm{I}(1)$ \\
\hline DI & -0.588 & $-5.849 * * *$ & $\mathrm{I}(1)$ & -0.558 & -8.970 *** & $\mathrm{I}(1)$ & -0.908 & $-12.99 * \star \star$ & $\mathrm{I}(1)$ \\
\hline GDP & -1.025 & $-6.658^{* * *}$ & $\mathrm{I}(1)$ & -0.298 & $-9.076^{\star \star *}$ & $\mathrm{I}(1)$ & -0.679 & $-12.97 * * \star$ & $\mathrm{I}(1)$ \\
\hline EC & $-2.387 * \star \star *$ & & $\mathrm{I}(0)$ & -0.888 & $-12.56^{\star \star \star}$ & $\mathrm{I}(1)$ & -0.356 & $-3.199 * * *$ & $\mathrm{I}(1)$ \\
\hline
\end{tabular}

Table 2

Pesaran's test of cross-sectional dependence

\begin{tabular}{|lllllll|}
\hline & CO2 & TA & TR & DI & GDP & EC \\
\hline CD-stat & $5.987^{\star \star \star}$ & $3.025^{\star \star \star}$ & $8.345^{\star \star \star}$ & $19.18^{\star \star \star}$ & $8.472^{\star \star \star}$ & $4.879 \star \star \star$ \\
\hline Off-diagonal elements & 0.517 & 0.407 & 0.632 & 0.513 & 0.559 & 0.476 \\
\hline Prob. & 0.000 & 0.002 & 0.000 & 0.000 & 0.000 & 0.000 \\
\hline
\end{tabular}

Table 3 delivers the empirical findings of POLS, FMOLS, and DOLS for basic models and robust models. From Table 3, we can perceive that obtained coefficient estimates from all three regressions are quite different from each other in terms of coefficient size, although all possess almost similar significance level. As the study measures international tourism through two proxies i.e., international tourism in number of arrivals (TA) and international tourism in current US\$ receipts (TR) to confirm the robustness of findings. The empirical findings reveal that tourism arrivals have a significant and negative impact on CO2 emissions according to FMOLS model and DOLS model, however, tourism arrival has significant and negative impact on $\mathrm{CO} 2$ in all three models. It conveys that a percentage increase in tourism arrivals negatively affects $\mathrm{CO} 2$ emissions by 0.640 percent in case of FMOLS estimator and 1.360 percent in case of DOLS estimator. The coefficient estimates of robust models reveal that 1 percentage increase in tourism receipts negatively influences $\mathrm{CO} 2$ emissions by 0.713 percent in case of POLS model, 0.040 percent in case of FMOLS model and 0.670 percent in case of DOLS model. In case of digital infrastructure, the findings of basic models reveal use of internet has negative impact in case of FMOLS model i.e., 1 percent increase in internet use result in decreasing $\mathrm{CO} 2$ emissions by 0.010 percent and use of internet has a positive impact on $\mathrm{CO} 2$ emissions in case of DOLS model revealing that 1 percent increase in internet use tends to increase CO2 emissions by 0.060 percent. 
The findings of robust models conclude that digital infrastructure leads to increase CO2 emissions in case of POLS and FMOLS models and decrease $\mathrm{CO} 2$ emissions in case of DOLS model. The coefficient estimates reveal that due to 1 percent upsurge in use of internet, CO2 emissions increase by 0.011 percent in case of POLS estimator and 0.010 percent in case of FMOLS estimator, however, CO2 emissions reduces by 0.150 percent in case of DOLS estimator. The findings of control variables reveal that GDP and energy consumption has significant and positive impact on $\mathrm{CO} 2$ emissions in all three basic regression models, however, in case of robust models, GDP and energy consumption have significant and positive impact on $\mathrm{CO} 2$ emissions in case of POLS and FMOLS models but these variables negatively influence CO2 emissions in case of DOLS regression.

Table 3

Results of panel estimation for Asian countries

\begin{tabular}{|c|c|c|c|c|c|c|}
\hline & \multicolumn{3}{|c|}{ Basic models } & \multicolumn{3}{|c|}{ Robust models } \\
\hline & POLS & FMOLS & DOLS & POLS & FMOLS & DOLS \\
\hline TA & 0.034 & $-0.640 * * \star$ & $-1.360 * \star *$ & & & \\
\hline TR & & & & $-0.713^{\star \star \star}$ & $-0.040 *$ & $-0.670^{\star \star \star *}$ \\
\hline DI & -0.006 & $-0.010 * * \star$ & $-0.060 * \star \star *$ & $-0.011^{\star}$ & $-0.010 * \star \star$ & $-0.150 * \star \star$ \\
\hline GDP & $4.555^{\star \star \star}$ & 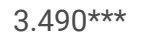 & 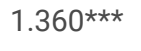 & $4.753^{\star \star \star}$ & $3.600 * \star \star$ & $-3.560 * \star \star$ \\
\hline EC & $0.545^{\star \star \star}$ & 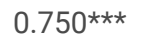 & 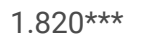 & 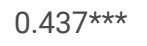 & $0.560 * \star \star$ & $-0.210 * \star \star$ \\
\hline
\end{tabular}

The focus variables of the study, international tourism measured by tourism arrivals have a significant negative impact on CO2 emissions in most regressions. This reveals that tourism arrival results in improving environmental quality by minimizing carbon emissions. These findings are in line with many previous studies such as (Leon et al. 2014; Dogan and Aslan 2017). Literature reveals that tourism arrival consumes green energy or less polluted energy as compared to industrial and agricultural sectors (Kocak et al. 2020). Furthermore, the robust measure of international tourism, tourism receipts also has a significant and negative impact on $\mathrm{CO} 2$ emissions in all three regressions. The existing literature reveals that wellorganized tourism can protect the environment by endorsing the usage of environmentally friendly transportation and technology. Literature also elaborates that tourism is included in the service sector and this sector is relatively cleaner than the agriculture and industrial sector (Grossman and Krueger 1995). There is a transitional shift from the agricultural and industrial sector to the services sector. Hence, tourism contributes more to enhancing quality of environment and produces lesser CO2 emissions. Paramati et al. (2017) study reported that tourism policies result in raising awareness regarding the protection of environment and can become an instrument to provide their efforts for ensuring reduction in environmental degradation.

The contribution of digitalization is increasing in $\mathrm{CO} 2$ emissions because the increased usage of computers, mobiles, and internet have increased the energy demand that contributes more to reducing quality of environment (Usman et al. 2021) and the production of digital sector-related material has contaminated the environment (20). Furthermore, the digital industry has the quality to encourage a culture that uses less carboninvolved goods, hence contributes to the expansion of a sustainable economy and society. The utilization of digital infrastructure in various sectors can ease energy efficiency by reducing footprints of $\mathrm{CO} 2$ emissions by shrinking energy consumption while encouraging economic development. The study done by Moran et al. (2016) reveals that digital infrastructure contributes significantly to preserving the use of energy in economic activities. The modern and digital society determined by digital infrastructure has encouraged the considerable development of the industrial sector and the whole economy (Ullah et al. 2021). Furthermore, digital infrastructure produces green and clean manufacturing processes to conserve costs, attainment of better economic activities in all sectors, and improvement in the efficiency of production, hence enhances quality of environment. Hence, the application of digital infrastructure has influenced the decision-making of consumers and producers regarding energysaving (Shabalov et al. 2021).

Table 4 delivers the findings of panel quantile regression for tourism arrivals and $\mathrm{CO} 2$ model. Where, the results show that the impact of tourism arrival on carbon emission is positive and statistically significant for lower quantiles (i.e., quantile 1 to quantile 5), statistically insignificant for quantile 6 th and 7 th, while positive and statistically significant for higher quantiles (i.e., quantile 8th to quantile 11 th ). These results conclude that due to the rise in tourism arrivals the quality of environment deteriorates at lower quantiles and quality of environment improves at higher quantiles. In the case of digital infrastructure, the findings show that use of internet has a statistically insignificant impact on CO emissions from 1 st quantile to 10th quantiles, but it exerts a statistically significant and positive impact on CO2 emissions at 11th quantile. The findings of GDP and energy consumption reveal that these two variables exert a positive and statistically significant impact on CO2 emissions from lower to higher quantiles considering their deteriorating effect on environmental quality. The robust model produces almost similar kinds of effects as shown by Table 5 . 
Table 4

Results of panel quantile regression

\begin{tabular}{|c|c|c|c|c|c|c|c|c|c|c|c|}
\hline & 0.05 & 0.10 & 0.20 & 0.30 & 0.40 & 0.50 & 0.60 & 0.70 & 0.80 & 0.90 & 0.95 \\
\hline TA & $0.302^{\star \star \star}$ & $0.360 * \star \star$ & $0.411^{\star \star \star}$ & $0.282^{\star \star \star}$ & 0.186 ** & 0.104 & -0.050 & $-0.438 * \star \star$ & $-0.964 * \star \star *$ & $-1.664 * \star \star$ & $-1.994 * \star \star$ \\
\hline DI & 0.002 & -0.001 & -0.003 & 0.001 & -0.001 & 0.000 & -0.004 & 0.004 & 0.015 & -0.004 & -0.038 ** \\
\hline GDP & $1.831^{\star \star \star \star}$ & $1.881^{\star \star \star}$ & $2.47^{\star \star *}$ & 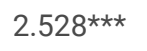 & $2.771^{\star \star \star}$ & $2.991 * \star \star$ & $3.430 * \star \star$ & $4.059 * \star \star$ & 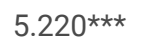 & $6.973^{\star \star \star}$ & $7.202^{\star \star \star}$ \\
\hline EC & $0.171^{\star * \star *}$ & $0.190 * \star \star$ & $0.275^{\star \star \star}$ & $0.409 * \star \star$ & $0.566^{\star \star \star}$ & $0.631^{\star * *}$ & 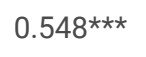 & $0.557 * \star \star$ & $0.591^{\star \star \star}$ & $0.709 * \star \star$ & $0.849 * * *$ \\
\hline C & $-18.76^{\star \star \star}$ & $-19.79 * \star \star$ & $-25.24^{\star \star \star}$ & $-24.05^{\star \star \star}$ & 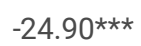 & $-25.51^{\star \star \star}$ & $-25.40 * \star \star$ & $-23.93^{\star \star \star}$ & $-24.35^{\star \star \star}$ & $-26.12^{\star \star \star}$ & $-23.58 * \star \star$ \\
\hline
\end{tabular}

Table 5

Results of panel quantile regression (robust)

\begin{tabular}{|c|c|c|c|c|c|c|c|c|c|c|c|}
\hline & 0.05 & 0.10 & 0.20 & 0.30 & 0.40 & 0.50 & 0.60 & 0.70 & 0.80 & 0.90 & 0.95 \\
\hline TR & 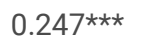 & $0.227^{\star \star \star}$ & $0.122^{*}$ & -0.002 & $-0.133^{\star}$ & $-0.368 * \star \star$ & $-0.670 * * *$ & 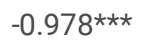 & 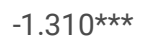 & 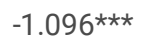 & $-1.148 * \star \star$ \\
\hline DI & 0.002 & 0.004 & 0.000 & 0.002 & $-0.007 *$ & -0.010 * & $-0.021^{\star \star *}$ & $-0.030 * \star \star *$ & $-0.024^{\star}$ & $-0.016^{\star}$ & $-0.027 *$ \\
\hline GDP & $1.913^{\star \star \star}$ & $1.828 * \star \star$ & $2.467^{\star \star \star}$ & $2.603^{\star \star \star}$ & 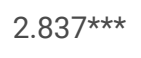 & $3.258^{\star \star \star \star}$ & $3.702^{\star \star \star}$ & $4.447^{\star \star \star}$ & $5.378 * \star \star$ & 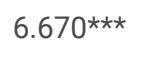 & $6.766^{\star \star \star}$ \\
\hline EC & $0.158^{\star \star \star \star}$ & $0.144^{\star \star \star}$ & $0.336 * \star \star *$ & $0.397^{\star \star *}$ & $0.510 \star \star \star *$ & $0.575^{\star \star \star}$ & $0.557 * \star \star$ & $0.660 * \star \star *$ & $0.652^{\star \star \star}$ & $0.692^{\star \star \star}$ & $0.800 * \star *$ \\
\hline C & $-20.36^{\star \star *}$ & $-18.94^{* * *}$ & $-22.07 * \star \star *$ & $-20.36 * \star \star$ & $-19.74^{\star \star \star}$ & $-18.15^{\star \star \star}$ & $-14.69 * * *$ & $-14.07^{* \star *}$ & $-13.04^{\star \star *}$ & $-24.95^{\star \star *}$ & $-24.79 * * *$ \\
\hline
\end{tabular}

\section{Conclusion And Policy Implications}

Since the industrial revolution, humans' social and economic activities have increased manifold, which is the main reason behind rising carbon emissions into the atmosphere. However, over the past few decades, the infusion of carbon into the atmosphere has gathered the pace. As a result, the world temperature is rising, and natural calamities such as floods, droughts, sea storms, severe fluctuations in weather, etc., appear more often. Therefore, environmental policymakers and world leaders have shown serious concerns over deteriorating environmental quality. Consistent with this view, many empirics have tried to analyze the factors that can lower the burden on the environment without compromising on the process of economic growth.

The main motivation behind this study is the importance of the tourism sector and digitalization in the economic development of a country and their potential effects on the country's environmental quality. For empirical analysis, the study applies the POLS, FMOLS, DOLS, and quantile regression techniques. The findings of the study confirmed that the tourism arrival and receipts negatively impact the $\mathrm{CO} 2 \mathrm{emissions}$ in the basic models with FMOLS and DOLS techniques. Similarly, the estimated coefficients of tourism arrival and receipts negatively impact the CO2 emissions in the robust models with POLS, FMOLS, and DOLS techniques. The estimates of digital infrastructure also exert a negative impact on the CO2 emissions in the basic and robust models with POLS, FMOLS, and DOLS estimation techniques. On the other side, in the basic quantile regression model, the estimates attached to tourism arrival are positive 5th quantile to 40th quantile and then turn negative from 60th quantile and onwards. Likewise, the estimates attached to tourism receipts in the robust quantile regression model are positive from quantile 5 to quantile 20 and negative and increasing from quantile 30 and onwards. Conversely, the estimates of digital infrastructure are insignificant in the basic quantile model at all quantiles except 95th. However, the estimated coefficients of digital infrastructure in the robust model are negative and rising from 40th quantile to 70th quantile and negative and declining from 80th quantile to 95th quantile.

On the basis of the above findings, some important policy implications are suggested for the concerned stakeholders. Our findings indicate that the rising tourism activities improve the environmental quality in selected countries. This means that the selected countries have adopted well-balanced ecological conservation strategies to attain sustainable development. These effects can be further strengthened by adopting ecotourism policies and inducting green infrastructure in the tourism sector. On the other side, digitalization also improves the environmental quality of the selected nations, which supports the idea that to control $\mathrm{CO} 2$ emissions smart products need to be promoted in the whole economy such as smart transportation, smart appliances in homes and offices, and smart green energy projects. Digitalization shifts the economy from physical resources to information resources, promoting environmental quality. Therefore, easy credit facilities should be provided to the industries and sectors that promote the use of green ICT products that are less energy-intensive.

\section{Declarations}

Ethical Approval: Not applicable

Consent to Particinate: I am free to contact anv of the neople involved in the research to seek further clarification and information Loading [MathJax]/jax/output/CommonHTML/fonts/TeX/fontdata.js 
Consent to Publish: Not applicable

Author's Contributions: This idea was given by Liu Wei. Liu Wei and Sana Ullah analyzed the data and wrote the complete paper. While Sana Ullah read and approved the final version.

Funding: Not applicable

Competing Interests: The authors declare that they have no conflict of interest.

Availability of data and materials: The datasets used and/or analyzed during the current study are available from the corresponding author on reasonable request.

\section{References}

Aslam, B., Hu, J., Majeed, M. T., Andlib, Z., \& Ullah, S. (2021). Asymmetric macroeconomic determinants of CO 2 emission in China and policy approaches. Environmental Science and Pollution Research, 1-14.

Aslan, A., Altinoz, B., \& Özsolak, B. (2021). The nexus between economic growth, tourism development, energy consumption, and CO 2 emissions in Mediterranean countries. Environmental Science and Pollution Research, 28(3), 3243-3252.

Azam, M., Alam, M. M., \& Hafeez, M. H. (2018). Effect of tourism on environmental pollution: Further evidence from Malaysia, Singapore and Thailand. Journal of cleaner production, 190, 330-338.

Bastida, L., Cohen, J. J., Kollmann, A., Moya, A., \& Reichl, J. (2019). Exploring the role of ICT on household behavioural energy efficiency to mitigate global warming. Renewable and Sustainable Energy Reviews, 103, 455-462.

Castellani, D., \& Pieri, F. (2013). R\&D offshoring and the productivity growth of European regions. Research Policy, 42(9), $1581-1594$.

Chan, A. P. C., Darko, A., Olanipekun, A. O., \& Ameyaw, E. E. (2018). Critical barriers to green building technologies adoption in developing countries: The case of Ghana. Journal of cleaner production, 172, 1067-1079.

Chen, X., Gong, X., Li, D., \& Zhang, J. (2019). Can information and communication technology reduce CO 2 emission? A quantile regression analysis. Environmental Science and Pollution Research, 26(32), 32977-32992.

Chien, F., Anwar, A., Hsu, C. C., Sharif, A., Razzaq, A., \& Sinha, A. (2021). The role of information and communication technology in encountering environmental degradation: Proposing an SDG framework for the BRICS countries. Technology in Society, 65, 101587.

Dogan, E., \& Aslan, A. (2017). Exploring the relationship among CO2 emissions, real GDP, energy consumption and tourism in the EU and candidate countries: Evidence from panel models robust to heterogeneity and cross-sectional dependence. Renewable and Sustainable Energy Reviews, 77 , 239-245.

Gokmenoglu, K. K., \& Eren, B. M. (2020). The role of international tourism on energy consumption: empirical evidence from Turkey. Current Issues in Tourism, 23(9), 1059-1065.

Gössling, S., \& Hall, C. M. (2006). An introduction to tourism and global environmental change. Tourism and global environmental change, 1-34.

Hussain, J., Khan, A., \& Zhou, K. (2020). The impact of natural resource depletion on energy use and CO2 emission in Belt \& Road Initiative countries: a cross-country analysis. Energy, 199, 117409.

Imran, S., Alam, K., \& Beaumont, N. (2014). Environmental orientations and environmental behaviour: Perceptions of protected area tourism stakeholders. Tourism management, 40, 290-299.

Kao, C., \& Chiang, M. H. (2001). On the estimation and inference of a cointegrated regression in panel data. In Nonstationary panels, panel cointegration, and dynamic panels. Emerald Group Publishing Limited.

Katircioglu, S. T., Feridun, M., \& Kilinc, C. (2014). Estimating tourism-induced energy consumption and CO2 emissions: The case of Cyprus. Renewable and Sustainable Energy Reviews, 29, 634-640.

Khattak, S. I., Ahmad, M., Khan, Z. U., \& Khan, A. (2020). Exploring the impact of innovation, renewable energy consumption, and income on CO2 emissions: new evidence from the BRICS economies. Environmental Science and Pollution Research, 1-16.

Koçak, E., Ulucak, R., \& Ulucak, Z. Ş. (2020). The impact of tourism developments on CO2 emissions: An advanced panel data estimation. Tourism Loading [MathJax]/jax/output/CommonHTML/fonts/TeX/fontdata.js 
Koenker, R. (2004). Quantile regression for longitudinal data. Journal of Multivariate Analysis, 91(1), 74-89.

Koenker, R., \& Bassett Jr, G. (1978). Regression quantiles. Econometrica: journal of the Econometric Society, 33-50.

Latif, M. T., Othman, M., Idris, N., Juneng, L., Abdullah, A. M., Hamzah, W. P., ... \& Jaafar, A. B. (2018). Impact of regional haze towards air quality in Malaysia: a review. Atmospheric Environment, 177, 28-44.

Moyer, J. D., \& Hughes, B. B. (2012). ICTs: do they contribute to increased carbon emissions?. Technological Forecasting and Social Change, 79(5), 919-931.

Naradda Gamage, S. K., Hewa Kuruppuge, R., \& Haq, I. U. (2017). Energy consumption, tourism development, and environmental degradation in Sri Lanka. Energy Sources, Part B: Economics, Planning, and Policy, 12(10), 910-916.

Nepal, R., Al Irsyad, M. I., \& Nepal, S. K. (2019). Tourist arrivals, energy consumption and pollutant emissions in a developing economy-implications for sustainable tourism. Tourism Management, 72, 145-154.

Ozcan, B., \& Apergis, N. (2018). The impact of internet use on air pollution: evidence from emerging countries. Environmental Science and Pollution Research, 25(5), 4174-4189.

Paramati, S. R., Alam, M. S., \& Lau, C. K. M. (2018). The effect of tourism investment on tourism development and C02 emissions: empirical evidence from the EU nations. Journal of Sustainable Tourism, 26(9), 1587-1607.

Park, Y., Meng, F., \& Baloch, M. A. (2018). The effect of ICT, financial development, growth, and trade openness on CO 2 emissions: an empirical analysis. Environmental Science and Pollution Research, 25(30), 30708-30719.

Pesaran, M. H., Shin, Y., \& Smith, R. J. (2001). Bounds testing approaches to the analysis of level relationships. Journal of applied econometrics, 16(3), 289-326.

Pesaran, M. H., Shin, Y., \& Smith, R. P. (1999). Pooled mean group estimation of dynamic heterogeneous panels. Journal of the American statistical Association, 94(446), 621-634.

Salahuddin, M., \& Alam, K. (2016). Information and Communication Technology, electricity consumption and economic growth in OECD countries: A panel data analysis. International Journal of Electrical Power \& Energy Systems, 76, 185-193.

Shabalov, M. Y., Zhukovskiy, Y. L., Buldysko, A. D., Gil, B., \& Starshaia, V. V. (2021). The influence of technological changes in energy efficiency on the infrastructure deterioration in the energy sector. Energy Reports, 7, 2664-2680.

Shin, Y., Yu, B., \& Greenwood-Nimmo, M. (2014). Modelling asymmetric cointegration and dynamic multipliers in a nonlinear ARDL framework. In Festschrift in honor of Peter Schmidt (pp. 281-314). Springer, New York, NY.

Usman, A., Ozturk, I., Hassan, A., Zafar, S. M., \& Ullah, S. (2021). The effect of ICT on energy consumption and economic growth in South Asian economies: an empirical analysis. Telematics and Informatics, 58, 101537.

Usman, A., Ozturk, I., Ullah, S., \& Hassan, A. (2021). Does ICT have symmetric or asymmetric effects on CO2 emissions? Evidence from selected Asian economies. Technology in Society, 67, 101692.

Van Heddeghem, W., Lambert, S., Lannoo, B., Colle, D., Pickavet, M., \& Demeester, P. (2014). Trends in worldwide ICT electricity consumption from 2007 to 2012. Computer Communications, 50, 64-76.

Zhang, C., \& Liu, C. (2015). The impact of ICT industry on CO2 emissions: a regional analysis in China. Renewable and Sustainable Energy Reviews, $44,12-19$.

Zhang, S., \& Liu, X. (2019). The roles of international tourism and renewable energy in environment: new evidence from Asian countries. Renewable energy, 139, 385-394.

Loading [MathJax]/jax/output/CommonHTML/fonts/TeX/fontdata.js 